\title{
LA CONSOLIDACIÓN DE LA AUTORIZACIÓN PARA TRABAJAR DEL EXTRANJERO MEDIANTE EL ALTA EN LA SEGURIDAD SOCIAL
}

\section{AUTHORIZATION CONSOLIDATION FOR FOREIGNERS TO WORK BY REGISTRATING WITH THE SOCIAL SECURITY}

\author{
Francisco Javier Fernández Orrico \\ Universidad de Miguel Hernández, Elche. España/Spain \\ orrico@umh.es
}

Recibido/Received: 19/01/2015

Modificado/Modified: 24/04/2015

Aceptado/Accepted: 29/04/2015

\section{RESUMEN}

A continuación se expone un estudio sobre el papel que juega el sistema de Seguridad Social en las autorizaciones administrativas para trabajar de los extranjeros, y otras cuestiones afines, en particular, las que fueron objeto de modificación por Ley Orgánica 2/2009, de 11 de diciembre, de reforma de la Ley Orgánica 4/2000, de 11 de enero, sobre derechos y libertades de los extranjeros en España y su integración social.

\section{PALABRAS CLAVE}

Trabajador extranjero, Seguridad Social, autorización administrativa para trabajar.

\section{SUMARIO}

1. Introducción. 2. Los visados de residencia y trabajo. 3. Autorización conjunta de residencia y trabajo. 4. La autorización de residencia y trabajo por cuenta ajena. 5. La autorización de residencia y trabajo por cuenta propia. 6 . Breves reflexiones finales. Bibliografía.

\begin{abstract}
Following a study on the role of the Social Security system in the administrative authorizations to work of foreigners, and other related issues, in particular those that were subject to modification by Organic Law 2/2009 of 11 exposed December reform of the Organic Law 4/2000 of 11 January on the rights and freedoms of foreigners in Spain and their social integration.
\end{abstract}

\section{KEYWORDS}

Foreign worker, Social Security, Administrative authorization to work.

\section{CONTENTS}

1. Introduction. 2. Residence visas and work. 3. Joint Authorization of residence and work. 4. Authorization of residence and gainful employment. 5. The authorization of residence and selfemployment. 6. Brief final thoughts. References. 


\section{INTRODUCCIÓN}

De un tiempo a esta parte, en particular en la primera mitad de la presente década poco se han prodigado las novedades en materia de la Seguridad Social de los trabajadores foráneos. Esta circunstancia, resulta ciertamente rara en Seguridad Social, pues sabido es que quienes habitamos en el mundo de la Seguridad Social, apenas tenemos oportunidad de profundizar en el estudio de la materia, precisamente por la transitoriedad de sus normas, a causa de la brevedad en muchos casos de su duración y la necesidad de comentar los preceptos que las sustituyen.

En esta ocasión, me centraré, sobre todo, en la última reforma de calado sobre extranjería que precisamente ha incidido en diversos aspectos que hacen referencia a la Seguridad Social de los trabajadores extranjeros. Dicha reforma tuvo lugar mediante Ley Orgánica 2/2009, de 11 de diciembre, de reforma de la Ley Orgánica 4/2000, de 11 de enero, sobre derechos y libertades de los extranjeros en España y su integración social (en adelante LO 2/2009), de la que cabría resaltar la importancia con que se dotó al alta en la Seguridad Social del trabajador extranjero como consolidación de la autorización administrativa de residencia y trabajo. El reglamento de desarrollo se hizo esperar, produciéndose algunas incertidumbres de aplicación, hasta que finalmente fue aprobado por Real Decreto 557/2011, de 20 de abril, por el que se prueba el Reglamento de la Ley Orgánica 4/2000, sobre derechos y libertades de los extranjeros en España y su integración social, tras su reforma por Ley Orgánica 2/2009 (en adelante RLOex).

Según el art. 10.1 LOex, "los extranjeros residentes que reúnan los requisitos previstos en esta Ley Orgánica y en las disposiciones que la desarrollen tienen derecho a ejercer una actividad remunerada por cuenta propia o ajena, así como a acceder al sistema de la Seguridad Social, de conformidad con la legislación vigente". La LO 2/2009, incluyó la precisión de que debía ostentar la condición de residente legal.

Sobre la forma de expresarlo, cabe comentar, que en lugar de referirse al derecho a un trabajo remunerado y a la Seguridad Social como una posibilidad de acceder al derecho "tendrán derecho"-, de la normativa precedente, se considera como un derecho actual al decir "tienen derecho". Parece dar a entender que tienen derecho de por sí sin necesidad de solicitud, solo por el hecho de reunir las condiciones, algo que no parece viable por el momento.

En el ámbito de la Función Pública, la reforma simplifica las condiciones de acceso de los extranjeros respecto a la redacción anterior del apartado 2 del art. 10, al remitirse a lo que prevea la Ley 7/2007, de 12 de abril, del Estatuto Básico del Empleado Público, cuyo art. 57.2 viene a reproducir en esencia lo establecido en el anterior apartado 2, al establecer que «los extranjeros con residencia legal en España podrán acceder a las Administraciones Públicas como personal laboral, en igualdad de condiciones que los españoles». Se mantiene, por tanto, la limitación de los extranjeros únicamente al acceso al empleo público como personal laboral, vetando todo ingreso en la Administración Pública con la condición de funcionario (Sempere Navarro y Hierro Hierro, 2009: 624).

\section{LOS VISADOS DE RESIDENCIA Y TRABAJO}

Sin duda el cambio de mayor calado de la Reforma de 2009, en relación con la Seguridad Social fue la exigencia de que el trabajador extranjero debía darse de alta en la Seguridad Social por el desempeño de una actividad, para que el visado de entrada en 
España consolide sus efectos, es decir, para que tenga eficacia la autorización de residencia y trabajo. Como es sabido, el visado válidamente expedido y en vigor, extendido en el pasaporte o documento de viaje o, en su caso, en documento aparte, es una condición que los extranjeros deben cumplir con carácter general si pretenden entrar en territorio español. Una clase de visado que se contempla es el de residencia y trabajo, "que habilita para la entrada y estancia por un período máximo de tres meses y para el comienzo, en ese plazo, de la actividad laboral o profesional para la que hubiera sido previamente autorizado. En este tiempo deberá producirse el alta del trabajador en la Seguridad Social, que dotará de eficacia a la autorización de residencia y trabajo, por cuenta propia o ajena. Si transcurrido el plazo no se hubiera producido el alta, el extranjero quedará obligado a salir del territorio nacional, incurriendo, en caso contrario, en la infracción contemplada en el artículo 53.1.a) de esta Ley" (art. 25 bis 2.d). LOex).

El cambio fundamental con respecto a la redacción anterior consiste en que antes no se consideraba un plazo para darse de alta en la Seguridad Social, sino que solo se exigía la obtención del visado en el plazo de un mes desde la notificación de la autorización para trabajar. Ahora se le da al trabajador extranjero un plazo de tres meses para darse de alta en la Seguridad Social desde la fecha del visado, previa la autorización administrativa. Lo que significa que los efectos de la autorización de residencia y trabajo no se producen con el visado (como antes), sino que esa autorización solo producirá efectos cuando se produzca el alta del trabajador en la Seguridad Social. La consecuencia del cambio, es que si finalmente no se produce el alta del trabajador, se le obliga a salir de España, y en caso de que tampoco salga el extranjero del territorio nacional incurre en la infracción grave del art. 53.1.a) LOex.

Este nuevo escenario obliga a las autoridades a un seguimiento del trabajador para la comprobación del cumplimiento de las obligaciones que comporta el visado, como se desprende del contenido del art. 70.9 del RLOex).

Debe distinguirse este visado del de residencia y trabajo de temporada de la letra e) "que habilita para trabajar por cuenta ajena hasta nueve meses en un período de doce meses consecutivos". La diferencia consiste en que sólo habilita para desempeñar el trabajo por cuenta ajena a diferencia del visado antes examinado que incluye el trabajo por cuenta propia, por lo que podría utilizarse como medio de entrada en España en la consolidación de una autorización de residencia y trabajo, desde luego más accesible que a través del visado no temporal.

\section{AUTORIZACIÓN CONJUNTA DE RESIDENCIA Y TRABAJO}

Cuando la reforma, establece los requisitos para que el extranjero pueda desempeñar una actividad no se centra tan solo en la obtención de la autorización administrativa para trabajar, sino que a diferencia de la redacción anterior, ésta vendrá acompañada de la autorización de residencia. Por eso, resulta significativo el cambio de denominación del Capítulo III, al pasar de titularse "del permiso de trabajo y regímenes especiales" a un titular más amplio: "de las autorizaciones para la realización de actividades lucrativas". De modo que el cambio no se ciñe solo al conocido durante muchos años como permiso de trabajo, sino que permite la regulación de la autorización de residencia conjunta con la de trabajo del extranjero. En ese sentido, la anterior redacción del art. 36.1 LOex, aludía a la exigencia de la correspondiente autorización para trabajar, sin perjuicio de que la misma 
habilitara al extranjero para residir durante el tiempo de su vigencia, extinguiéndose si al transcurrir un mes desde la notificación al empresario de su concesión no se solicitase el correspondiente visado. En cambio, la actual redacción prevé que "los extranjeros mayores de dieciséis años precisarán, para ejercer cualquier actividad lucrativa, laboral o profesional, de la correspondiente autorización administrativa previa para residir $\mathrm{y}$ trabajar". Precisándose a continuación el alcance de ambas autorizaciones al señalarse que «la autorización de trabajo se concederá conjuntamente con la de residencia, salvo en los supuestos de penados extranjeros que se hallen cumpliendo condenas o en otros supuestos excepcionales que se determinen reglamentariamente».

En consecuencia, no estamos ante una autorización de trabajo que al mismo tiempo produce efectos de autorización de residencia como antes de la reforma, sino que se trata de dos autorizaciones (la de residencia y la de trabajo) diferenciadas que se otorgan al simultáneamente.

Como ya se ha anticipado, no es el visado, sino que "la eficacia de la autorización de residencia y trabajo inicial se condicionará al alta del trabajador en la Seguridad Social" (art. 36.1 LOex), que como mínimo, deberá ser anterior al inicio de la actividad para respetar la normativa en materia de Seguridad Social, y además, el plazo máximo para darse de alta en la Seguridad Social, a los efectos de que produzca efecto la citada autorización deberá ser de tres meses desde la expedición del visado que habilita para la entrada durante ese tiempo. Esta clase de visado se regula por el art. 70 RLOex), cuando la actividad que se pretenda ejercer en España sea por cuenta ajena, y por el art. 108 del mismo cuerpo legal, de forma similar cuando lo sea por cuenta propia, en cuyo caso lo importante, es que se consiga dicha autorización que está subordinada al cumplimiento de los requisitos previstos en los arts. 103 a 107 de la citada disposición (Álvarez Rodríguez, 2011: 405).

Respecto de aquellas autorizaciones en las que se prevé el visado de residencia y trabajo de temporada, éste habilita para trabajar por cuenta ajena hasta un período de 9 meses dentro de doce meses consecutivos, por lo que habrá que estar a lo previsto en el art. 25 bis.2e) LOex, y «en caso de que en el plazo de un mes desde su entrada en España no exista constancia de que el trabajador ha sido dado de alta en el régimen correspondiente de la Seguridad Social, el órgano competente podrá resolver la extinción de la autorización (art. 174.4 RLOex).

\subsection{Coordinación con las administraciones públicas}

El último inciso del art. 36.2 LO 4/2000, hace referencia a algo que no deja tener importancia y que sugerí, como consecuencia de mi labor inspectora para mejorar el control de las altas de los extranjeros en la Seguridad Social. Concretamente, el mandato consiste en que "la Entidad Gestora comprobará en cada caso la previa habilitación de los extranjeros para residir y realizar la actividad". Comprobación que lógicamente deberá realizar antes de dar de alta al trabajador extranjero en la Seguridad Social.

En efecto, antes de la reforma de 2009, se echaba de menos una mejora en la coordinación con la Entidad gestora, en supuestos de solicitudes de alta sin autorización para trabajar. En tales casos, una vez detectada la situación por la administración de la Seguridad Social, ésta debería advertir al empresario acerca de su intento de afiliación indebida del trabajador extranjero en el mismo instante que se produce la solicitud, momento en que presumiblemente el trabajador extranjero todavía no ha iniciado su actividad. Para ello, debería exigirse la presentación simultánea de la Resolución o tarjeta por la que se otorga al trabajador la correspondiente autorización para trabajar, y en donde 
figuran los límites de actividad y territoriales del permiso. Esta previsión ya existía antes de la reforma, si bien con rango reglamentario, y se encuentra en el art. 42.1 del Real Decreto 84/1996, de 26 de enero, por el que se aprueba el Reglamento General sobre inscripción de empresas y afiliación, altas, bajas y variaciones de datos de trabajadores en la Seguridad Social, según el cuál: "A efectos de la afiliación y el alta para su inclusión en el sistema y en el correspondiente régimen de Seguridad Social en los términos previstos en la ley, se equiparan a los españoles los extranjeros que residan o se encuentren legalmente en España y hayan obtenido una autorización administrativa previa para trabajar, en los casos en que sea legal o reglamentariamente exigible.

Para tal inclusión, las solicitudes de afiliación y alta de los trabajadores extranjeros, tanto por cuenta propia como por cuenta ajena, deberán acompañarse de la documentación acreditativa de su nacionalidad y, a excepción de aquellos a los que resulte de aplicación la normativa comunitaria, de la correspondiente autorización para trabajar o del documento que acredite la excepción de la obligación de obtenerla, además de los datos y documentos requeridos para las de los trabajadores españoles".

En consecuencia, la Administración de la Seguridad Social ya tenía obligación de examinar la autorización y podía, en función de la actividad a desarrollar por el trabajador extranjero, admitir o no la afiliación o alta en la Seguridad Social.

Una pequeña apreciación sobre el Organismo a quien compete la comprobación de la autorización de residencia y trabajo. Es evidente que el legislador quiso referirse al correspondiente Servicio Común, que no es otro que la Tesorería General de la Seguridad Social (TGSS), en lugar de la Entidad Gestora, con la excepción del Instituto Social de la Marina, que como es sabido se constituye como una Entidad de ámbito nacional de Derecho público con personalidad jurídica propia y tiene como finalidad la asistencia a los trabajadores del mar, tanto en España como en el extranjero.

Lo fundamental, es que el organismo correspondiente debe cerciorarse antes de dar de alta en la Seguridad Social a cualquier extranjero, que se encuentra en posesión de la correspondiente autorización administrativa para trabajar, pues se han dado no pocos casos de trabajadores que han sido dados de alta en la Seguridad Social sin encontrarse en posesión de aquella autorización, lo que provoca un conflicto no exento de importancia al comprobarse por parte de la Inspección de Trabajo y Seguridad Social tales circunstancias, sancionando por no tener autorización para trabajar y comunicando a la TGSS la baja de oficio del trabajador en la Seguridad Social desde su inicio.

\subsection{Otras cuestiones cercanas a la autorización administrativa}

a) Contrato de trabajo. Con respecto a la contratación de un extranjero por un empleador, la reforma -art. 36.4 LOex-, además de solicitar la autorización administrativa previa para residir y trabajar, exige "que en todo caso deberá acompañarse del contrato de trabajo que garantice una actividad continuada durante el periodo de vigencia de la autorización". Con ello parece que el legislador ha querido dotar de mayor seguridad a la efectiva contratación del trabajador extranjero al tiempo que permite un mayor control de la empresa que solicita su contratación, si bien tal obligación ya existía a nivel reglamentario.

b) Derechos laborales del extranjero por trabajar sin autorización administrativa. Un aspecto del mayor interés en el que incide la nueva redacción del art. 36.5 LOex, es el que se refiere a los efectos que produce la carencia de la autorización de residencia y trabajo, no solo respecto a las responsabilidades del empresario en forma de sanciones por la 
comisión de las correspondientes infracciones, entre las que se encuentran las de Seguridad Social, sino sobre todo por las consecuencias que conlleva esa omisión desde el punto de vista del trabajador extranjero. La carencia de la autorización de residencia y trabajo (antes solo trabajo), al igual que antes de la reforma, "no invalidará el contrato de trabajo respecto a los derechos del trabajador extranjero, ni será obstáculo para la obtención de las prestaciones derivadas de supuestos contemplados por los convenios internacionales de protección a los trabajadores u otras que pudieran corresponderle, siempre que sean compatibles con su situación". En consecuencia, se mantienen los mismos efectos en la vertiente laboral del contrato de trabajo que antes de la LO 2/2009, es decir, se considerará que pese a la falta de autorización para residir y trabajar en España, los derechos del contrato laboral que han firmado empresario y trabajador se mantienen incólumes, como pueden ser, entre otros, el abono de indemnización y salarios de tramitación por despido improcedente a trabajador extranjero sin autorización para trabajar por la validez del contrato respecto a los derechos del trabajador pero atención solo a estos efectos se considerará válido el contrato de trabajo, pues desde la perspectiva del empresario no producirá efectos salvo los que se refieran a las diversas responsabilidades que conlleven su ausencia. Y es que, "si bien el contrato de trabajo del extranjero, sin la preceptiva autorización, está afectado de la sanción de nulidad que establece la ley (art. 7.1 ET) en relación con el art. 36.1 de la LOex, sin embargo, la misma ley salva la sanción de nulidad proclamando su validez respecto a los derechos del trabajador afectado" (STS 13 septiembre 2013 [RJ 2013, 7309]).

c) Prestaciones de Seguridad Social. La redacción vigente concreta más los casos en que sería posible el acceso a las prestaciones, habida cuenta de la dispersa doctrina judicial que tenía que aplicar una frase tan difusa como la que señalaba, que la carencia de autorización no "será obstáculo para la obtención de las prestaciones que pudieran corresponderles". Con la nueva redacción, esta inconcreción se despeja al remitirse a los supuestos que establecen los convenios internacionales. No obstante, en la mayoría de los casos, nuestros tribunales acertaron a la hora de interpretar la redacción anterior de la norma al otorgar diversas prestaciones. En estos casos, lo que se plantea es, si, no siendo posible la incorporación del trabajador extranjero en el sistema de la Seguridad Social, por no encontrarse en posesión de la autorización de residencia y trabajo, tendría derecho a las prestaciones que dispensa la Seguridad Social.

La respuesta al interrogante, pasa por distinguir el origen de la contingencia concreta, pues si la misma deriva de un accidente de trabajo o de una enfermedad profesional, el trabajador extranjero no autorizado para trabajar accede a los derechos que se derivan de la relación laboral no autorizada, sin que, por el momento, en tal supuesto exista base suficiente, para que puedan otorgarse prestaciones contributivas del sistema de la Seguridad Social, cuando el origen del riesgo actualizado derive de una contingencia común. De manera que cuando se trata de un accidente de trabajo, la reciprocidad se considera reconocida presuntamente, tanto en el ámbito internacional (Convenios OIT 19 y 97) como nacional, al establecerse la plena equiparación de los trabajadores extranjeros y los nacionales con respecto a las indemnizaciones por contingencias profesionales, quedando amparado todo extranjero, con independencia de su situación frente a los accidentes de trabajo y enfermedades profesionales. De ese modo, nos encontramos, con una asimilación con respecto al trabajador extranjero sin autorización de residencia y trabajo, del principio de automaticidad de las prestaciones (principio recogido en el art. 125.3 LGSS), en virtud del cual en el caso de incumplimiento de las obligaciones del empresario para con el trabajador (alta en la Seguridad Social, cotización, etcétera) la 
entidad gestora anticipa el pago de la prestación, sin perjuicio de repercutir, a su vez ulteriormente, contra el empresario infractor (sobre el particular, en Martínez Barroso y Tascón López, 2014). Algo similar tiene lugar con el derecho de los trabajadores menores de dieciséis años a las prestaciones de asistencia sanitaria, pese a no haber sido dados de alta ni haber cotizado a la Seguridad Social, precisamente por prohibición legal (art. 10 decreto 2766/1967, de 16 de noviembre).

En suma, cuando los extranjeros se encuentran autorizados para trabajar, celebran el correspondiente contrato de trabajo y son dados de alta en la Seguridad Social, pueden acceder, en su caso a las prestaciones contributivas de la Seguridad Social, en las mismas condiciones que los trabajadores españoles.

d) Protección por desempleo. Entre las prestaciones que se han otorgado por los tribunales, aun sin haber obtenido con carácter previo la autorización para trabajar, cabe destacar por lo inusual, la prestación por desempleo, si bien habiendo obtenido previamente la autorización de residencia (SSTS 18 marzo y 12 noviembre 2008). Sin embargo, el art. 36.5, LOex, en la redacción de la LO 2/2009, rompe con esa interpretación y establece categóricamente que, "en todo caso, el trabajador que carezca de autorización de residencia y trabajo no podrá obtener prestaciones por desempleo". De manera que no sólo se exige la autorización para residir en España, también la autorización para trabajar sin la que desde el 13-12-2009 no es posible causar derecho a prestaciones por desempleo. Por lo tanto, se exige como expresamente señala la norma, autorización de residencia y trabajo, que se otorgan conjuntamente.

e) La prestación y la situación administrativa del extranjero. En el último inciso del art. 36.5 LOex se advierte que "salvo en los casos legalmente previstos, el reconocimiento de una prestación no modificará la situación administrativa del extranjero". Con ello, el legislador quiere dejar constancia que el hecho de que se reconozca una prestación al extranjero no significa que cambie su situación administrativa, en el sentido de que el acceso a alguna prestación le habilite para que se le reconozca una autorización de residencia o de residencia y trabajo, salvo -matiza-, en los casos legalmente previstos.

f) Reciprocidad según la nacionalidad del extranjero. El apartado 6 del art. 36, reproduce de forma idéntica la redacción del apartado 4 de la anterior versión de 2009 , LOex, cuando establece que "en la concesión inicial de la autorización administrativa para trabajar podrán aplicarse criterios especiales para determinadas nacionalidades en función del principio de reciprocidad". Manifestación del principio de reciprocidad que se aplica en cualquier Estado. Si acaso, y por coherencia con el resto del artículo al referirse a las autorizaciones, debiera haberse referido no solo a la autorización administrativa para trabajar, sino también a la de residencia.

g) Supuesto de retorno limitado del trabajador extranjero. El apartado 7 del art. 36 LOex, recuerda que "no se concederá autorización para residir y realizar una actividad lucrativa, laboral o profesional, a los extranjeros que, en el marco de un programa de retorno voluntario a su país de origen, se hubieran comprometido a no retornar a España durante un plazo determinado en tanto no hubiera transcurrido dicho plazo". Es claro que se refiere al caso particular de aquellos trabajadores extranjeros que se acogieron al Real Decreto Ley 4/2008, de 19 de septiembre, y posterior desarrollo por Real Decreto 1800/2008, de 3 de noviembre, por los que se establece la posibilidad de que los trabajadores extranjeros con derecho a la prestación contributiva por desempleo puedan retornar a su país de origen mediante la capitalización en dos plazos de la citada prestación como estímulo para que inicien su actividad en su país, si bien uno de los requisitos que se 
les exige es que asuman el compromiso "de retornar a su país de origen y el de no retornar a España en el plazo de tres años para residir y/o realizar una actividad lucrativa o profesional por cuenta propia o ajena". Evidentemente es a estos plazos a los que se refiere el citado apartado $7 \mathrm{del}$ art. 36 LOex. Plazos, por otro lado, que han transcurrido sobradamente en la mayoría de los casos de quienes se acogieron a esta fórmula.

h) Participación de trabajadores extranjeros en sociedades. El último apartado del artículo 36.8 LOex, previene que "reglamentariamente se determinarán las condiciones y requisitos para hacer posible la participación de trabajadores extranjeros en sociedades anónimas laborales y sociedades cooperativas". Parece dar a entender que, en principio se refiere a participación en sociedades en las que el socio no se limita a participar mediante un capital sino que su participación lo es aportando su trabajo en la misma, para lo que en principio debe estar en posesión de la autorización de residencia y trabajo y aquellas otras condiciones que por su condición de extranjero puedan ser exigidas por los reglamentos, sin que ello deba menoscabar "la igualdad de trato en las condiciones laborales y de Seguridad Social", como establece el art. 2 bis. 2. letra h) LOex, al enumerar los principios en que se basa la política inmigratoria.

\section{LA AUTORIZACIÓN DE RESIDENCIA Y TRABAJO POR CUENTA AJENA}

De forma específica el art. 38 LOex se ocupa de regular la autorización de residencia y trabajo del extranjero. Pero del trabajo realizado por cuenta ajena, es decir, que reúne las características del art.1.1 del Estatuto de los Trabajadores como son, que se realice de forma personal, voluntaria, dependiente y por cuenta ajena. Conviene que se analicen las características y su procedimiento.

a) La situación nacional de empleo. La vigente redacción del art. 38 LOex, desciende al detalle en lo que se refiere a la autorización de residencia y trabajo por cuenta ajena. Así el apartado 1, prevé que "para la concesión inicial de la autorización de residencia y trabajo, en el caso de trabajadores por cuenta ajena, se tendrá en cuenta la situación nacional de empleo". La nueva redacción se detiene en explicar en que consiste esa "situación nacional de empleo", al establecer que "la situación nacional de empleo será determinada por el Servicio Público de Empleo Estatal con la información proporcionada por las Comunidades Autónomas y con aquella derivada de indicadores estadísticos oficiales y quedará plasmada en el Catálogo de Ocupaciones de Difícil Cobertura. Dicho catálogo contendrá una relación de empleos susceptibles de ser satisfechos a través de la contratación de trabajadores extranjeros y será aprobado previa consulta de la Comisión Laboral Tripartita de Inmigración. Igualmente, se entenderá que la situación nacional de empleo permite la contratación en ocupaciones no catalogadas cuando de la gestión de la oferta se concluya la insuficiencia de demandantes de empleo adecuados y disponibles". En suma, como podía suponerse, la concesión de autorizaciones de residencia y trabajo a extranjeros se otorgarán cuando el sector de empleo demandado sea escaso y no suficientemente atendido.

Se hace referencia a diversas instituciones y fuentes: el Servicio Público de Empleo Estatal, la información proporcionada por las Comunidades Autónomas, los indicadores estadísticos oficiales, Catálogo de Ocupaciones de Difícil Cobertura, Comisión Laboral Tripartita de Inmigración... creo que son demasiadas instancias a las que es preciso acudir para una cuestión tan simple como la determinación de cuáles son los trabajos que no se cubren en España. Quizá la razón de este proceder se deba a que de un tiempo a esta parte, 
se observa un temor a que cualquier decisión pueda tacharse de no haber sido adoptada con las garantías adecuadas y por eso se hace ver que se establecen diversos filtros que aseguren la imparcialidad de quienes establecen las autorizaciones. Por otro lado, existe el riesgo de que tantas cautelas conduzcan a lo contrario de lo que se quiere evitar: la falta de transparencia, pues no es fácil el control de tantas instancias y al mismo tiempo una inevitable demora derivada de tan laborioso proceso.

Termina el apartado 2 del art. 38 LOex, estableciendo que se determinarán reglamentariamente los requisitos mínimos para considerar que la gestión de la oferta de empleo es considerada suficiente. Tales requisitos se contienen en el art. 66 RLOex.

b) Procedimiento. El apartado 3 del art. 38 LOex, muestra gráficamente todo el proceso de concesión de la autorización de residencia y trabajo por cuenta ajena inicial, lo que resulta del mayor interés pues anteriores normativas a nivel de Ley no contemplaban tanto detalle. De hecho, se observa una multiplicidad de deberes que deben cumplir tanto el empresario que desea contratar a un extranjero (solicitud de cobertura de un puesto vacante, adjuntar contrato de trabajo, resto de documentación exigible, y como último paso el alta en la Seguridad Social, una vez el extranjero se encuentre en España) como al propio extranjero (residencia en un tercer país, visado, suscribir el contrato).

De todos estos requisitos, el que más nos concierne es el que se refiere al alta en la Seguridad Social. Obsérvese que se dice: "se produzca el alta del trabajador", lo que podría inducir a confusión sobre quien asume la obligación de dar el alta en la Seguridad Social al trabajador extranjero, que en todo caso es de la empresa. De modo que si no se produjera el alta en el plazo de tres meses desde el visado, la autorización de residencia y trabajo, sabemos no tendrá efecto y por tanto el trabajador no estará autorizado para trabajar. En suma, si no se produjera el alta del trabajador extranjero en la Seguridad Social dentro del plazo de tres meses desde el visado, distinguimos esquemáticamente las siguientes situaciones:

- Si no llega a trabajar:

- La autorización de residencia y trabajo no producirá efectos y por tanto el trabajador no estará autorizado para trabajar, y además deberá marcharse de España.

- Y si en lugar de salir permanece en España, cabe si se le detecta, la imposición de una infracción grave del art. 53.1.a).

- Si trabaja sin darse de alta con carácter previo (poco probable pues espera la autorización) o transcurridos los tres meses desde el visado:

- La sanción no sería una falta de alta en la Seguridad Social sino que conforme a los explicado sería una falta de autorización de residencia y trabajo del art. 54.1.d) LOex [infracción muy grave sancionada a partir de 10.001 euros desde 13-12-2009, según el art. 55.1.c) LOex].

c) Comunicaciones por diversas incidencias. El apartado 4 del art. 38 LOex, contiene algunas incidencias que no contemplaba la redacción anterior, según se produzca el desistimiento de la solicitud de autorización o no pudiera iniciarse la relación laboral una vez obtenida la autorización de residencia y trabajo. En el primer caso, el empresario debe comunicar el desistimiento de la solicitud de autorización si, mientras se resuelve la autorización o el visado, desaparece la necesidad de contratar al extranjero o se modifican las condiciones del contrato de trabajo que sirvió de base a la solicitud. En el otro caso, supone un escalón más, ya se han dado todos los pasos para el inicio del trabajo del extranjero, es decir, cuando el extranjero habilitado se halla en España y el empresario ha llegado a registrar en los Servicios Públicos de Empleo el contrato de trabajo y ha 
formalizado el alta del trabajador en la Seguridad Social. Pues bien, si no pudiera iniciarse la relación laboral, el empresario debe comunicarlo a las autoridades competentes.

Dos cuestiones me sugieren este deber de comunicación (desistimiento o no inicio del trabajo). La primera acerca de a quien debe comunicarse: a la autoridad laboral de la Comunidad Autónoma o ante la Delegación o Subdelegación del Gobierno. Cabe pensar que será ante la misma autoridad a que se refiere el apartado anterior que hubiera sido, en su caso, la que finalmente aprueba la autorización de residencia y trabajo, pero tampoco el apartado 3 señala cuál es de las dos anteriores.

En el caso del desistimiento de la autorización se dice algo más, pues el empresario deberá comunicarlo ante "las autoridades competentes" pero sigue sin conocerse la autoridad competente. La pista para conocer quien es, la proporciona el apartado 8 del art. 38 , al señalar que "la concesión de la autorización inicial de trabajo, en necesaria coordinación con la que corresponde al Estado en materia de residencia, corresponderá a las Comunidades Autónomas de acuerdo con las competencias asumidas en los correspondientes Estatutos". Esta cuestión de reparto de competencias tiene el peligro de incrementar la demora en la concesión de autorización.

La segunda cuestión hace referencia a las motivaciones que justifican la comunicación del desistimiento en seguir adelante con la autorización o, el de una vez obtenido todos los trámites incluido el alta en la Seguridad Social del trabajador "no pudiera iniciarse la relación laboral", como apunta la norma. El precepto no exige una justificación de las causas del desistimiento ni siquiera de las razones, de las causas por las que no se ha podido iniciar la actividad laboral, lo que, en ocasiones podría dejar al trabajador en una situación de clara vulnerabilidad al no ver el fruto de tantas gestiones realizadas para conseguir trabajo en España. Por tanto, a mi parecer es importante que, las disposiciones reglamentarias que desarrollen este aspecto de las autorizaciones, fijen por un lado, la autoridad competente con claridad y por otro, que se acompañe un escrito junto con la documentación necesaria que acredite las razones del desistimiento o de la imposibilidad de iniciar el trabajo por parte del extranjero.

Quizá la respuesta se encuentre en el art. 53.2.a), al señalar que cuando el empresario tenga constancia de que el trabajador se halla legalmente en España habilitado para el comienzo de la relación laboral, estará exento de dar de alta en la Seguridad Social al trabajador, cuando comunique a las autoridades competentes la concurrencia de razones sobrevenidas que puedan poner en riesgo objetivo la viabilidad de la empresa o que, conforme a la legislación, impidan el inicio de dicha relación.

En el caso de que el empresario no alegue alguna de estas razones (desistimiento o no poderse iniciar la actividad), y transcurra el plazo establecido se incurrirá en una infracción grave según el citado artículo, que llevará aparejada la obligación del empresario de sufragar los gastos de viaje del extranjero [art. 55.1.b) LOex].

d) Autorización inicial de residencia y trabajo. A primera vista poco parece que haya variado la regulación de la normativa de autorizaciones iniciales de residencia y trabajo. Sin embargo, si se observa con atención se descubren notables diferencias. Así, mientras que en la normativa anterior, se decía que "el permiso de trabajo podrá limitarse a un determinado territorio, sector o actividad", en la vigente redacción parece que se endurece esa posibilidad al establecerla como obligatoria cuando señala el apartado 5 del art 38 LOex, que "la autorización inicial de residencia y trabajo se limitará, salvo en los casos previstos por la Ley y los Convenios Internacionales firmados por España, a un determinado territorio y ocupación. En lo que respecta a la limitación territorial, se refiere, al limite de «un ámbito geográfico" de la autorización de residencia y trabajo. Mientras 
que se han sustituido los términos "sector" y "actividad" por el de "ocupación" para referirse a la concreta actividad que desempeña el trabajador, quizá para sintetizar algo más la descripción del trabajo, que necesariamente será por cuenta ajena. Hay que presumir que la autorización que contenga la concreta ocupación indicará asimismo -como hasta ahora-, el sector de la actividad, pues este matiz es importante de cara a la consideración de la situación nacional de empleo.

Por lo que se refiere a la duración de la autorización, el apartado 5 del art. 38 LOex (a diferencia de la normativa anterior que establecía una duración inferior a cinco años) se remite a lo que establezca el reglamento, que prevé en su art. 63.5 RLOex, que "La autorización inicial de residencia temporal y trabajo por cuenta ajena tendrá una duración de un año y se limitará, en lo relativo al ejercicio de la actividad laboral y salvo en los casos previstos por la Ley y los Convenios Internacionales firmados por España, a un ámbito geográfico y a una ocupación determinada". Por lo que en principio ésta será la duración que deberá otorgarse.

e) Autorización limitada a un determinado territorio y ocupación. Una cuestión de interés que se plantea a diario es si la posesión de una autorización de residencia y trabajo por cuenta ajena que habilita para trabajar en un ámbito geográfico u ocupación diferente a la que desempeña el trabajador extranjero puede ser equiparada a la situación de un trabajador sin ninguna autorización para trabajar. En la normativa anterior, ambas situaciones tenían las mismas consecuencias a efectos sancionadores. Daba igual que no tuviera permiso de trabajo o que sí lo tuviera pero en otro territorio o sector de la actividad. En ese sentido, si se otorgaba una autorización para trabajar y no se respetaba cualquiera de las citadas limitaciones, debía considerarse como si no se encontrara en posesión de la autorización para trabajar, y por tanto, la empresa podría ser sancionada caso de detectarse la presencia del trabajador en la actividad, con sanciones muy graves, a partir de seis mil un euros, en su grado mínimo [art 55.1.c) en relación con el art. 54.1.d) LOex, anterior a la redacción de 2009]. Tal actuación se justificaba, «por entender que, cuando la autorización establece un marco geográfico o funcional, en definitiva impone unas condiciones limitativas de su validez, por lo que una actividad fuera de tales confines no resulta amparada por dicha autorización y habrá de entenderse que se ejerce sin ella» (Instrucción num. 5/2006, de 5 de junio de 2006, de la Dirección General de la ITSS, sobre la actuación a realizar por la Inspección de Trabajo y Seguridad Social en relación con el arraigo laboral de los trabajadores extranjeros, colaboración con autoridades administrativas, cambio actividad y ámbito geográfico de los trabajadores con autorizaciones de residencia y trabajo, y altas en la Seguridad Social de los que carecen de éstas, pág. 7). Este razonamiento no me convencía, pues, cuando en la LOex (anterior a la reforma de 2009), se tipificaba la infracción -artículo 54.1.d)-, se refería a la «contratación de trabajadores extranjeros sin haber obtenido la correspondiente autorización de trabajo...», sin otras limitaciones. Por lo que no parecía que estuviera tipificada la contratación de extranjeros que dispongan de autorización para un sector de actividad y/o ámbito geográfico distinto de aquel en el que fueron contratados, pues para ello deberían especificarse tales circunstancias en el precepto infringido. En ese precepto, no se tipifica el incumplimiento de tales limitaciones, sino tan sólo la falta de autorización de trabajo. Por lo que, en estos supuestos, promover una sanción por falta de autorización de trabajo suponía ir más allá de lo que se disponía como infracción.

En otras palabras, es verdad que el desempeño de una actividad diferente de la que se encuentra autorizado el extranjero para trabajar puede suponer un actividad irregular 
merecedora, en su caso, de ser tipificada como una infracción, pero desde luego, no puede en modo alguno equipararse a la falta absoluta de autorización para trabajar, que es precisamente lo único que preveía el precepto tipificador antes de la reforma de 2009, pues en puridad el trabajador extranjero ha obtenido con carácter previo la autorización de trabajo. Por eso, no parecía equitativo que se equipararan ambas situaciones.

La realidad era que las Administraciones de la Seguridad Social venían detectando solicitudes de alta en la Seguridad Social de trabajadores que estaban autorizados para trabajar en un sector determinado, concretamente una gran mayoría en el sector del Hogar familiar doméstico, que daban lugar a su encuadramiento en el anterior Régimen Especial de Empleados de Hogar (Sistema Especial del Régimen General de la Seguridad Social, desde 1 de enero de 2012), y sin embargo, en ocasiones se les daba de alta en otro Régimen distinto, la mayor parte de las veces en el General. La explicación de ello, se encuentra en que las altas en la Seguridad Social de los trabajadores, se tramitan en su gran mayoría, mediante el denominado sistema de Remisión Electrónica de Datos (RED), en donde es obligatorio incluir el Número de Identificación del Extranjero (NIE), sin posibilidad de adjuntar la autorización para trabajar. De modo que, por un lado, la TGSS resolvía afirmativamente sobre el alta del trabajador en la Seguridad Social, sin tener plena certeza del contenido de la autorización de trabajo del extranjero, y, por otro, la empresa puede entender que al aceptarle la administración de la Seguridad Social el alta del extranjero ello supone un reconocimiento implícito y, por tanto, puede desempeñar la actividad porque tiene una autorización para trabajar, sin fijarse en el detalle de los sectores concretos que puede desempeñar el trabajador extranjero o en el ámbito geográfico de actividad, de ahí la importancia de la presentación "física" de la afiliación o alta en la Seguridad Social en el mismo instante de la solicitud.

Para evitar estos problemas, ofrecí una solución similar a la de la reforma cuando manifesté: "creo muy importante que la Entidad gestora correspondiente, debería realizar la labor comprobatoria consistente en: primero, la correlación entre la actividad autorizada al extranjero y, el Régimen de la Seguridad Social en que se encuadra, y en segundo lugar, si esa actividad autorizada se corresponde con la que pretende realizar". Si bien, lo expresé con más detalle de como finalmente ha dispuesto la Ley, pues distinguía en el primer caso, "que dicha labor correspondería, sin duda a la TGSS, y respecto al segundo punto, pienso que el Servicio Público de Empleo correspondiente, en su labor de control de los contratos de trabajo, podría ser el encargado de comprobar que la actividad que figura en el contrato se corresponde con la autorizada. Sólo en el caso de que superados tales filtros persista la incorrección, o exista duda sobre la misma sería cuando se trasladaría a la Inspección de Trabajo y Seguridad Social, el expediente para su investigación. Pero insisto, en el caso de los extranjeros tales precauciones deberían acreditarse antes del inicio en la actividad del trabajador extranjero" (Fernández Orrico, 2006: 7-8).

Esta situación me recuerda el de las empresas que dan de alta en la Seguridad Social a trabajadores, pero fuera del plazo reglamentario, figurando ese movimiento en el propio parte, de modo que aparece dado de alta en la fecha de presentación del alta, pero se retrotrae a una fecha anterior. Parece una conducta menos grave que aquella en la que se detecta por la Inspección a un trabajador sin haber sido dado de alta en la Seguridad Social, y a sí se contempla desde 2011 por la normativa sancionadora del orden social. También en esto parece que el legislador atendió mis sugerencias.

Como señalé explícitamente, "creo que, en ambos casos, pero sobre todo para el supuesto de trabajadores dados de alta en otra actividad de la autorizada o en otro ámbito territorial autorizado para ejercer la actividad, debería, al menos, tenerse en cuenta estas 
circunstancias y atenuar la sanción, si acaso, calificándola de grave o en casos de manifiesto error, incluso leve, a tenor de las razones expuestas" (Fernández Orrico, 2006: 7). Pues bien, parece que el legislador ha recogido el guante y ha reconocido tales situaciones de mucha menor gravedad, hasta calificarlas como leves, en lugar de muy graves, con la incorporación de dos nuevas letras d) y e), al art. 52 LOex. El peligro que podría plantearse es la posibilidad de que la empresa asuma el riesgo de contratar trabajadores con autorización en diferentes ocupaciones o ámbitos geográficos, sabedora de que tan solo incurriría en infracción leve, sancionable con multa hasta de 500 euros como máximo.

f) Supuestos de renovación de las autorizaciones. Si se observan con detenimiento las causas por las que se prorrogan las autorizaciones de residencia y trabajo se aprecian diferencias de importancia que conviene resaltar. Así pues, la autorización de residencia y trabajo se renovará a su expiración:

1) "Cuando persista o se renueve el contrato de trabajo que motivó su concesión inicial, o cuando se cuente con un nuevo contrato" [letra a) art. 38.6. LOex].

La anterior redacción, la renovación, se contemplaba no solo por el contrato en el caso de que persistiera o se renovase sino que se incluía también la oferta de trabajo. En cambio, la nueva redacción restringe la renovación al contrato de trabajo, dejando fuera la oferta de trabajo.

2) "Cuando por la autoridad competente, conforme a la normativa de la Seguridad Social, se hubiera otorgado una prestación contributiva por desempleo" [letra b) art. 38.6. LOex].

La versión anterior equiparó la duración de la renovación a la duración de la prestación por desempleo. Ahora aquella duración deberá establecerse por vía reglamentaria, como el resto de causas de renovación.

3) "Cuando el extranjero sea beneficiario de una prestación económica asistencial de carácter público destinada a lograr su inserción social o laboral” [letra c) art. 38.6. LOex].

También en esta cuestión la redacción anterior establecía que la duración de la autorización lo era por el plazo de duración de tales prestaciones.

4) "Cuando concurran otras circunstancias previstas reglamentariamente, en particular, los supuestos de extinción del contrato de trabajo o suspensión de la relación laboral como consecuencia de ser víctima de violencia de género" [letra d) art. 38.6. LOex].

Se añade como causa de renovación de autorización de residencia y trabajo por cuenta ajena, la condición de víctima de violencia de género, en los casos de suspensión o extinción de la relación laboral. Al igual que en la anterior redacción, "a partir de la primera concesión, las autorizaciones se concederán sin limitación alguna de ámbito geográfico u ocupación" (art. 38.7 LOex).

\section{LA AUTORIZACIÓN DE RESIDENCIA Y TRABAJO POR CUENTA PROPIA}

La autorización de trabajo por cuenta propia no ha cambiado en lo esencial, salvo que ahora se denomina, de residencia y trabajo y que en determinados supuestos la autorización de trabajo por cuenta propia corresponde a las autonomías. Se regula en el art. 37 LOex y su desarrollo reglamentario se contiene en los arts. 103 a 109 del RLOex, idéntico al anterior, de modo que "para la realización de actividades económicas por cuenta propia habrá de acreditarse el cumplimiento de todos los requisitos que la 
legislación vigente exige a los nacionales para la apertura y funcionamiento de la actividad proyectada, así como los relativos a la suficiencia de la inversión y la potencial creación de empleo, entre otros que reglamentariamente se establezcan" (apartado 1). Entre esos otros requisitos, se encuentran: que el trabajador no se encuentre irregularmente en territorio español, carezca de antecedentes penales, tanto en España como en sus países anteriores de residencia durante los últimos cinco años, por delitos previstos en el ordenamiento español, no figure como rechazable en el espacio territorial de países con los que España tenga firmado un convenio en tal sentido, que haya transcurrido el plazo de compromiso de no regreso a España del extranjero (3 años), asumido por éste en el marco de su retorno voluntario al país de origen, que se haya abonado la tasa por tramitación de la autorización de residencia temporal (art. 105.2 RLOex).

A este respecto, llama la atención que el art. 101 RLOex, exija el cumplimiento de los 18 años, del extranjero en residencia temporal y trabajo por cuenta propia, autorizado para permanecer en España por un período superior a 90 días e inferior a cinco años, pues como señala el Dictamen 515/2011, del Consejo de Estado, sobre el Proyecto del Reglamento, la limitación a los mayores de 18 años, aun siendo razonable, no cuenta con suficiente base legal, puesto que el Código de Comercio admite al comerciante menor de 18 años (art. 5) y proclama para los extranjeros el principio de ley personal (art. 15). Asimismo, el art. 9 de la Ley 20/2007, de 11 de julio, del Estatuto del Trabajo Autónomo, establece que "los menores de dieciséis años no podrán ejecutar trabajo autónomo ni actividad profesional, ni siquiera para sus familiares". Pese a todo ello, al remitirse el art. 37.1 a los requisitos que se establezcan por el Reglamento (Charro Baena, Sánchez Trigueros, 2009:656), y este de la edad mínima es uno de ellos, no parece que pueda objetarse jurídicamente el hecho de que los menores de 18 años extranjeros no puedan ejercer la actividad por cuenta propia.

En la nueva redacción del art. 37 LOex, se añaden dos apartados para especificar que «la autorización inicial de residencia y trabajo por cuenta propia se limitará a un ámbito geográfico no superior al de una Comunidad Autónoma, y a un sector de actividad», determinándose su duración reglamentariamente (apartado 2).

Asimismo, se introduce algo que ya se ha incorporado al vigente reglamento de desarrollo, como es que "la concesión de la autorización inicial de trabajo, en necesaria coordinación con la que corresponde al Estado en materia de residencia, corresponderá a las Comunidades Autónomas de acuerdo con las competencias asumidas en los correspondientes Estatutos" (apartado 3).

También en el caso de los trabajadores extranjeros por cuenta propia, se contempla infracción leve en el supuesto de trabajadores dados de alta en una actividad diferente de la autorizada o en otro ámbito territorial autorizado para ejercer la actividad, como señala el apartado cincuenta y cinco del artículo único LO 2/2009, que incorpora la letra d) al artículo 52 LOex. Cabe comentar a este respecto, que la falta de autorización de trabajo por cuenta propia, siempre que se estuviera en posesión de la autorización de residencia, ya constituía una infracción leve [art. 52.c) LOex], por lo que ambas posibilidades se equiparan en lo que a la calificación de la infracción se refiere. En consecuencia, no se le ve el sentido -a diferencia de lo antes examinado respecto del trabajador extranjero por cuenta ajena-, de esta nueva letra d) pues los efectos son iguales (infracción leve), ya se carezca de autorización de trabajo por cuenta propia o se haya obtenido para diferente ocupación, sector de actividad, o ámbito geográfico, siempre que se encuentre trabajador extranjero en posesión de autorización de residencia. Y ello, sin perjuicio de que se mantenga la calificación de infracción grave, cuando se produzca la comisión de una 
tercera infracción leve, siempre que en el año anterior hubiera sido sancionado por dos faltas leves de la misma naturaleza [art. 53.e) LOex].

\section{BREVES REFLEXIONES FINALES}

Las novedades que incorporó la LOex, relativas al sistema de la Seguridad Social, han de calificarse como positivas, con sus claroscuros que toda iniciativa legislativa contiene, pues del estudio que se acaba de analizar se desprende un serio intento del legislador de dotar de mayor seguridad jurídica a los trabajadores extranjeros y a los empresarios que los contratan, en aspectos tales como, la exigencia de que se dé de alta en la Seguridad Social al extranjero para que su autorización administrativa produzca plenos efectos; la expulsión del trabajador extranjero que finalmente no se ha dado de alta, en el plazo establecido para consolidar la citada autorización; la distinción entre carecer de autorización para trabajar y encontrarse en posesión de autorización administrativa para trabajar en un territorio y ocupación diferente al que figura en la autorización otorgada; el control que evite situaciones por las que se dé de alta a trabajadores extranjeros sin permiso de trabajo; y en fin, otras cuestiones que fueron objeto de controversias, como el criterio de denegar las prestaciones por desempleo al trabajador extranjero, por falta de autorización administrativa para trabajar, al contrario del criterio seguido por la Jurisprudencia.

\section{BIBLIOGRAFÍA}

ÁlVAREZ RODRÍGUEZ, A. (2011). "Comentario al artículo 25 bis de la Ley Orgánica 4/2000" Cavas Martínez, F. (dir.) Comentarios a la Ley de Extranjería y su nuevo reglamento. Madrid: Cizur Menor. Civitas Thomson Reuters.

CHARRO BAENA, P. y SÁNCHEZ TRIGUEROS, C. (2011). "Comentario al artículo 37 de la Ley Orgánica 4/2000” Cavas Martínez, F. (dir.) Comentarios a la Ley de Extranjería y su nuevo

Reglamento. Madrid: Cizur Menor. Civitas Thomson Reuters.

FERNÁNDEZ ORRICO, F. J. (2006). "La actuación de la Inspección de Trabajo y Seguridad Social ante la irregular contratación de extranjeros en España”. En V Congreso de la Inspección de Trabajo y Seguridad Social, tercer panel: "La inmigración: actuación en permisos y condiciones de trabajo". Salamanca, octubre, publicado en la base de datos del Foro del Conocimiento de la Inspección de Trabajo y Seguridad Social.

MARTÍNEZ BARROSO, M. R. y TASCÓN LÓPEZ, R. (2014). "El extranjero "sin papeles" ante los riesgos profesionales (a propósito de una doctrina recientemente unificada por las sentencias del tribunal supremo de 9 de junio y 7 de octubre de 2003 y algunas cuestiones todavía en el aire tras la última reforma de la "ley de extranjería")". Valladolid, Información Laboral, núm. 14.

SEMPERE NAVARRO, A. V. y HIERRO HIERRO, J. (2009). Comentarios a la Ley 7/2007, de 12 de abril, del Estatuto Básico del Empleado Público. Madrid: Cizur Menor, Thomson Aranzadi. 


\section{Breve currículo:}

\section{Francisco Javier Fernández Orrico}

Profesor Titular de Derecho del Trabajo y de la Seguridad Social de la Universidad Miguel Hernández desde 2010. Subinspector de Empleo y Seguridad Social (1988-2010 en excedencia). Gestor Administrativo (no ejerciente). Licenciado en Ciencias de la Educación (Universidad Literaria de Valencia) Autor de más de 250 publicaciones de contenido laboral, la mayoría sobre diversas cuestiones actuales de Seguridad Social, en particular sobre protección social. 